\section{耍 Heighten Science P U B L I C I T I O N S Corporation ISSN 2576-9529}

\title{
Association between bh4/bh2 ratio and Albuminuria in Hypertensive Type -2 Diabetic patients
}

\author{
Jose Aviles-Herrera ${ }^{1}$, Karla C Arana-Pazos ${ }^{1}$, Leonardo Del \\ Valle-Mondragon ${ }^{2}$, Carolina Guerrero-García ${ }^{1}$ and Alberto \\ Francisco Rubio-Guerra ${ }^{1 *}$ \\ 'Metabolic and Research Clinic, Hospital General de Ticomán SS DF, México DF. Mexican \\ Group for Basic and Clinical Research in Internal Medicine, Mexico \\ Instituto Nacional de Cardiología, México
}

\section{*Address for Correspondence: Dr. Alberto Francisco Rubio Guerra, Motozintla \# 30, Col Letran Valle, México, Tel/Fax: (52 555) 53935 84; Email: clinhta@hotmail.com}

Submitted: 14 December 2017

Approved: 28 December 2017

Published: 29 December 2017

Copyright: @ 2017 Herrera JA. et al. This is an open access article distributed under the Creative Commons Attribution License, which permits unrestricted use, distribution, and reproduction in any medium, provided the original work is properly cited.

Keywords: Tetrahydrobiopterin; Dihydrobiopterin $\mathrm{BH} 4 / \mathrm{BH} 2$ ratio; Albuminuria; Endothelial dysfunction

\section{Abstract}

Endothelial dysfunction and inflammation play a key role in the pathophysiology of diabetic nephropathy; Tetrahydrobiopterin $(\mathrm{BH} 4)$ is an essential cofactor for nitric oxide synthase, when $\mathrm{BH} 4$ is reduced to dihydrobiopterin (BH2), endothelial dysfunction is induced.

Purpose: The aim of this study is to evaluate the relationship between the levels of biopterins with albuminuria in type-2 diabetic hypertensive patients.

Methods: We studied 30 hypertensive type-2 diabetic patients in whom biopterins levels were measured by reverse phase high performance liquid chromatography with fluorescence detection. Additionally, $24 \mathrm{~h}$ urinary albumin excretion was also measured (nephelometry). The levels of biopterins and albuminuria were correlated with the Pearson correlation coefficient.

Results: We did not find a significantly correlation between biopterins levels and albuminuria, However, we found a significantly inverse correlation $(\mathrm{R}=-0.498, \mathrm{p}<0.005)$ between the $\mathrm{BH} 4 / \mathrm{BH} 2$ ratio and albuminuria.

Conclusion: Our results suggest that the $\mathrm{BH} 4 / \mathrm{BH} 2$ ratio instead of biopterins levels may be a marker of nephropathy in hypertensive type-2 diabetic patients.

\section{Introduction}

Diabetic nephropathy (DN) is the most common cause of chronic kidney disease (CKD) worldwide; DN is also an important cause of premature mortality in diabetic patients [1].

Endothelial dysfunction (ED), is a common feature among type-2 diabetic patients, and is associated with urinary albumin excretion; indeed, microalbuminuria is considered a marker of endothelial dysfunction, as well as a predictor of nephropathy and coronary heart disease; it is also a risk factor for mortality in diabetic and nondiabetic patients [2].

Tetrahydrobiopterin (BH4) is an essential cofactor for the nitric oxide synthase (eNOS) regulation, this cofactor have an important role in regulating nitric oxide (NO) and superoxide production by eNOS; When the bioavailability of BH4 for eNOS is reduced, due to a decrease in the synthesis of the cofactor or because it is oxidized to dihydrobiopterin (BH2), electron transfer from eNOS becomes uncoupled from L-arginine oxidation, and the enzyme produces superoxide instead of NO, leading to endothelial dysfunction [3]. Recent studies show that $\mathrm{BH} 4 / \mathrm{BH} 2$ ratio may be even 
more important than the absolute BH4 levels for an adequate nitric oxide mediated endothelial function [4].

This study was conducted to evaluate whether circulating biopterin levels are correlated with albuminuria in hypertensive type-2 diabetic patients.

\section{Patients and Methods}

A total of 30 hypertensive patients with type- 2 diabetes mellitus with more than 12 months' from the diagnosis, and without previous treatment with thiazolindinediones, statins, GLP-1 analogues, or ACE inhibitors, nor with angiotensin receptor antagonists, were included.

To avoid influence of physical activity level on albuminuria, patients were recommended not to perform exercise in the 3 days before urine recollection.

In all of them, $\mathrm{BH} 4$ and $\mathrm{BH} 2$ were measured by reverse phase high performance liquid chromatography with fluorescence detection. All venous samples were collected in the morning after a 12-h overnight fast, and fasting glycemia (glycose oxidase) and HbA1c were measured from those samples. Twenty-four-hour urinary albumin excretion (nephelometry) was also performed.

\section{Patients with any of the following diagnoses were excluded from the study}

Decompensated diabetes mellitus (fasting blood glucose $>250 \mathrm{mg} / \mathrm{dl}$ ); heart, hepatic, or renal failure; evidence of valvular heart disease; heart block or cardiac arrhythmia; acute coronary syndrome or cerebrovascular disease six months before the study's initiation; autoimmune disease, pregnancy; urinary tract infection, fever or a history of alcohol abuse and/or psychotropic drugs.

The study was conducted with the approval of the Research and Medical Ethics Committee of our hospital, in accordance with the Helsinki declaration. Participants gave informed, written consent before their inclusion in the study protocol.

\section{Statistical Analysis}

Data are presented as the mean \pm standard deviation. The relationship between circulating biopterin levels and $24 \mathrm{~h}$ albumin excretion was assessed by Pearson's correlation coefficient.

\section{Results}

Baseline patient characteristics are shown in table 1 . We did not find a significantly correlation between BH4 levels and albuminuria ( $\mathrm{r}=-0.33, \mathrm{p}=0.067)$, nor with $\mathrm{BH} 2$ levels $(r=0.15, p>0.43)$. However, we found a significantly inverse correlation $(R=$ $-0.49, \mathrm{p}<0.005$ ) between the $\mathrm{BH} 4 / \mathrm{BH} 2$ ratio and albuminuria (Figure 1 ).

\begin{tabular}{|c|c|}
\hline Table 1: Basal Characteristics of Patients. & Patients \\
\hline Age (years & $60 \pm 9$ \\
\hline Gender $(\mathrm{M} / \mathrm{F})$ & $16 / 14$ \\
\hline Glycemia $(\mathrm{mg} / \mathrm{dl})$ & $133 \pm 29$ \\
\hline Hb A1c & 6 \\
\hline Low Density Lipoproteins $(\mathrm{mg} / \mathrm{dl})$ & $125 \pm 29$ \\
\hline Body Mass Index $\left(\mathrm{Kg} / \mathrm{m}^{2}\right)$ & $30.4 \pm 5.1$ \\
\hline Blood pressure $(\mathrm{mm} \mathrm{Hg})$ & $175 \pm 16 / 93 \pm 8.8$ \\
\hline BH4 $(\mathrm{nmol} / \mathrm{L})$ & $5.23 \pm 1.3$ \\
\hline BH2 $(\mathrm{nmol} / \mathrm{L})$ & $9.9 \pm 2.6$ \\
\hline BH4/BH2 Ratio & $0.701 \pm 0.14$ \\
\hline Albuminuria $(\mathrm{Mg})$ & $236.4 \pm 72$ \\
\hline History of DM2 & 8.3 \\
\hline History of Hypertension & 11.3 \\
\hline
\end{tabular}




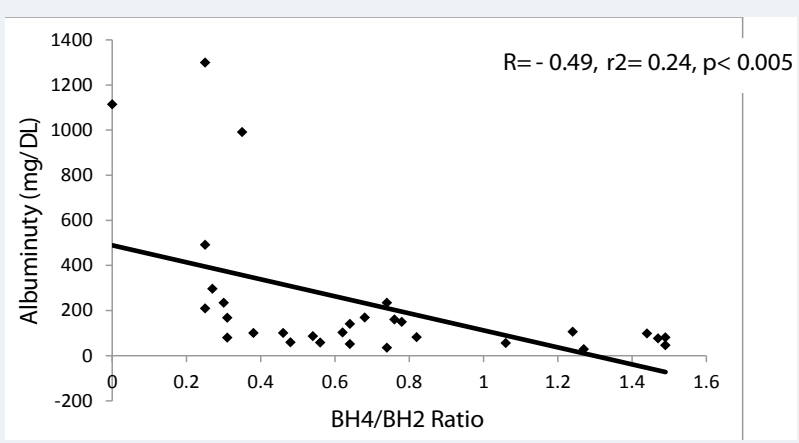

Figure 1: Correlation between the bh4/bh2 ratios and urinary albumin excretion.

\section{Discussion}

In the current study we investigated whether circulating levels of $\mathrm{BH} 4$ and $\mathrm{BH} 2$ were associated with albuminuria in hypertensive type-2 diabetic patients, although we failed to find any correlation between both biopterins and urinary albumin excretion, we found a significantly association for the $\mathrm{BH} 4 / \mathrm{BH} 2$ ratio with albuminuria . It is important to say that in our work; our patients were ACE/ARB-naïve and statinnaïve because those drugs have been shown to raise circulating levels of $\mathrm{BH} 4$ and to decrease those of $\mathrm{BH} 2$ [3].

Plasma levels of biopterins reflect their endothelial levels, BH4 has been implicated in the regulation of endothelial function, when oxidative stress is increased in the endothelial cell, BH4 is oxidized to dihydrobiopterin, and this fact favors eNOS uncoupling, under those conditions, molecular oxygen is reduced to form superoxide, leading to endothelial dysfunction [5]. Then; an inverse relation between BH4 and albuminuria is expected, although in our study did not reach significance [4].

Some studies have shown that endothelial dysfunction stimulates inflammation, and is involved in the genesis of end organ damage in diabetic patients, including chronic kidney disease. In fact, several studies have demonstrated the role of reduction of endothelial function in the setting of diabetic nephropathy [6]. And the opposite is also true; the presence of albuminuria is an important predictor of endothelial dysfunction in diabetic patients [7].

Inflammation induced by endothelial dysfunction plays an important role in the development of albuminuria in diabetic patients [8], however, for the first time, the current study demonstrated a significant relationship between the $\mathrm{BH} 4 / \mathrm{BH} 2$ ratios (but not biopterin levels) with albuminuria. As this ratio includes information about the levels of both biopterins, may be a more sensitive and reliable marker of endothelial dysfunction and glomerular injury than the isolate values of BH4 or BH2 [9]. Our results appeared to support this idea, since this ratio had an inverse correlation with urinary albumin excretion in our patients.

Our results may have therapeutic implication, the beneficial effects of inhibitors of the renin-angiotensin system and statins to ameliorate renal damage may be due, at least in part, with their effect on endothelial function. In addition, $\mathrm{BH} 4$ may be used as a therapeutic option, since $\mathrm{BH} 4$ restores endothelial function and reduces the production of superoxide in type 2 diabetic patients, via a nitric oxide pathway in short studies [9].

\section{Conclusion}

Our data suggest that the $\mathrm{BH} 4 / \mathrm{BH} 2$ ratio, (but not biopterin levels) is associated with albuminuria in type 2 diabetic normotensive patients. This explains, at least in part, the mechanisms that join type- 2 diabetes mellitus, oxidative stress, endothelial dysfunction, inflammation, and diabetic kidney damage. 


\section{References}

1. Walker JD. An update on diabetic renal disease. Br J Diabetes Vasc Dis. 2010; 10: 219-223. Ref.: https://goo.gl/tuKN34

2. Rubio AF, Vargas H, Lozano JJ, Escalante BA. Corrrelation between circulating adhesión molecules levels and albuminuria in type 2 diabetic hypertensive patients. Kydney Blood Press Res. 2009; 32: 106-109. Ref.: https://goo.gl/Hez4TN

3. Rubio-Guerra AF, Vargas-Robles H. Ramos-Brizuela LM. Escalante-Acosta BA. Is tetrahydrobiopterin a therapeutic option in diabetic hypertensive patients? Integr Blood Press Control. 2010; 3: 125-132. Ref.: https://goo.gl/zwyA7u

4. Takeda M, Yamashita T, Shinohara M, Sasaki N, Takaya T. Nakajima $K$ et al. Plasma tetrahydrobiopterin/dihydrobiopterin ratio. A posible marker of endothelial dysfunction. Cir J. 2009; 955-962. Ref.: https://goo.gl/osbbAE

5. Bauersachs J, Widder JD. Tetrahydrobiopterin, endothelial nitric oxide synthase, and mitochondrial function in the heart. Hypertension. 2009; 53: 907-908. Ref.: https://goo.gl/CCUCjF

6. ChanWB, Chan NN, Lai CW, So WY, Lo MK, et al. Vascular defect beyond the endothelium in type II diabetic patients with overt nephropathy and moderate renal insufficiency. Kidney International. 2006; 70: 711-716. Ref.: https://goo.gl/YhMdFA

7. Lim SC, Logerfo FW, Caballero AE, Horton ES, Smakowski $\mathrm{P}$, et al. Soluble intercellular molecule, vascular $\mathrm{C}$ adhesion molecule, and impaired microvascular reactivity are early markers of vasculopathy in type 2 diabetic individuals without microalbuminuria. Diabetes care. 1999; 22: 18651870. Ref.: https://goo.gl/P35yJp

8. Taslipinar A, Yaman H, llker M, Demirbas S, Saglam M, et al. The relationship between inflammation, endothelial dysfunction and proteinuria in patients with diabetic nephropathy. Scan J Clin \& Lab Invest. 2011; 71: 606-612. Ref.: https://goo.gl/bwMGrD

9. Rubio-Guerra AF, Vargas-Robles H, Del Valle-Mondragon L, Lozano-Nuevo JJ, Escalante-Acosta BA Association between the levels of circulating adhesion molecules and biopterins in type-2 diabetic normotensive patients adhesion molecules and biopterins. Endocr Metab Immune Disord Drug Targets. 2012; 12: 243-246. Ref.: https://goo.gl/5FDzXL 